\title{
Catálogo de freiles clérigos que ocuparon cargos en la Orden de Calatrava (Edad Media)
}

\author{
Catalogue of Office-Holding Clerical Brethren of the Order of \\ Calatrava (Middle Ages)
}

\author{
Manuel Ciudad Ruiz \\ Manuel.ciudad1@hispavista.cl
}

\section{RESUMEN}

Desde su nacimiento la Orden de Calatrava presentó una estructura dúplice. Por un lado estaba la rama militar, compuesta por los freiles caballeros, y por otra la rama clerical formada por los freiles clérigos. La mayor importancia de la rama militar, junto con la escasez de datos conservados sobre los clérigos calatravos, ha hecho que tradicionalmente la atención de cronistas e investigadores se haya fijado en los caballeros, quedando la investigación sobre los clérigos en un segundo plano. Por dicha razón la identidad personal de los clérigos de Calatrava ha permanecido casi a oscuras. El presente trabajo supone un esfuerzo por presentar una relación de los freiles clérigos en la época medieval, con los cargos que ocuparon, ampliando en la medida de lo posible los datos ya conocidos y aportando otros nuevos.

Palabras clave: Orden de Calatrava, Freiles clérigos, Prior de Calatrava, Sacristán Mayor, Convento de Calatrava, Priores formados, Capellanes de los Reyes, Prior del Maestre, Prior del Comendador Mayor, Prior del Clavero, Capellanes de Sevilla.

\begin{abstract}
The Order of Calatrava was founded as a hybrid system. On the one hand, there was a military branch consisting of knight brethren. On the other hand, there was a religious branch formed by clerical brethren. Given the importance of the military wing, and considering the scarcity of records on the clerical brethren of Calatrava, chroniclers and historians have focused on the knights while neglecting research on the clergy. Hence, little is known of the personal identity of the clerics of Calatrava. This study aims to establish a list of clerical brethren in the Middle Ages, along with the positions they held, expanding the information already known and adding to this new data.
\end{abstract}

Key words: Order of Calatrava, Clerical Brethren, Prior of Calatrava, Sacristan, Convent of Calatrava, Trained Priors, the King's Chaplains, Prior of the Master, Prior of the Grand Commander, Prior of the Clavero, Chaplains of Seville.

Sumario: 1. La estructura institucional de la Orden de Calatrava y su evolución. 2. Los freiles clérigos: número e identidad. 3. Catálogo de freiles clérigos. 
La rama clerical de la Orden de Calatrava estaba compuesta por los freiles clérigos profesos y por los novicios. La misión de los clérigos calatravos era atender el culto divino, proporcionar asistencia espiritual y sacramental a los freiles caballeros, orar por su triunfo en la guerra frente a los musulmanes y rezar por los difuntos de la Orden. La asistencia espiritual a los miembros de la Orden se hacía bien en el Convento central bien en distintos castillos a donde se destinaban a los freiles clérigos. Con el tiempo se crearon distintos prioratos menores que junto con el de Calatrava venían a cubrir las principales áreas del señorío de la Orden: Campo de Calatrava, la tierra de Zorita, la de Toledo y la de Andalucía en la Corona de Castilla, y Alcañiz y Valencia en la Corona de Aragón

\section{LA ESTRUCTURA INSTITUCIONAL DE LA ORDEN DE CALATRAVA Y SU EVOLUCIÓN}

Desde sus comienzos la Orden de Calatrava presentó una estructura doble: Por un lado estaba la rama militar y por otra la rama clerical formada por los freiles clérigos. Entre los siglos XII y XVI, la estructura institucional de la Orden sufrió una serie de transformaciones, siendo el resultado de un largo proceso en el que intervinieron varios factores, unos internos, como la progresiva ampliación y consolidación de su señorío (lo que incluye también sus derechos, propiedades y rentas), la consolidación del maestrazgo a finales del siglo XIII, o el proceso de señorialización experimentado por los miembros de la Orden desde mediados de la centuria citada; y otros externos, como las intervenciones de la Santa Sede sobre la Orden, la pugna con los abades de Morimundo por la cuestión del nombramiento del Prior de Calatrava, las tensiones por la jurisdicción y rentas con los diversos poderes episcopales o los intentos de control por parte de las distintas monarquías peninsulares donde los calatravos estuvieron presentes. Los factores antedichos provocaron en muchas ocasiones que las transformaciones sufridas por el entramado institucional de la Orden no estuvieran exentas de tensiones de todo tipo y también fueron responsables de la ampliación progresiva de la estructura institucional de la Orden desde un esquema muy simple en sus comienzos a mediados del siglo XII hasta la relativa complejidad de la misma a comienzos del siglo XVI.

Dentro de la estructura de la Orden la rama clerical fue objeto igualmente de transformaciones que permitieron a ésta adaptarse a las nuevas necesidades, tanto de índole espiritual como material. Arriba hemos hechos referencia a una serie de factores internos y externos como causantes del desarrollo institucional de la Orden. Dentro de los primeros, la expansión de la Orden por Aragón y por el sur peninsular al compás de los avances de la Reconquista obligó a adecuar las estructuras de la Orden a la nueva realidad territorial. Así, se crearon nuevas encomiendas, pero también los prioratos donde los caballeros alejados del Convento central podían recibir asistencia espiritual y cumplir sus obligaciones sacramentales.

A finales del siglo XIV se van a crear los llamados prioratos formados, aunque más que la creación de prioratos nuevos que vinieran a sumarse a los ya existentes, se trató de una elevación de categoría a la vez que una uniformización de los priora- 
tos existentes, incluidos los que ejercían la función de capellanes de las principales dignidades de la Orden. Esta reorganización de la rama clerical, contemporánea con el despegue económico del Convento central, hay que atribuirla a la conjunción de dos tipos de factores: Uno sería el incremento en el número de freiles clérigos que pudo haberse producido hacia finales del siglo XIV, con el consiguiente aumento del peso específico de la rama clerical. El otro tipo de factores se derivarían del proceso de señorialización que atravesaba la Orden desde mediados del siglo XIII y que en principio había dejado fuera a los freiles clérigos. Es posible, aunque no se detecta en la documentación conservada, que los clérigos de la Orden, finalmente afectados también por el proceso aludido, presionaran para conseguir una cierta equiparación con los comendadores, además de un mayor volumen de rentas. Sólo así se justificaría, además, la multiplicación de los prioratos y la creación de los situados en el Campo de Calatrava, cuya función no era la de atender las necesidades sacramentales de los miembros de la Orden residentes en el Campo, que debían acudir para ello al Convento central, sino la de interés de la Orden por controlar tanto las limosnas procedentes de las ermitas que luego serían cabeza del priorato como la ortodoxia de las manifestaciones de la religiosidad popular que en ellas se celebraban. Un caso distinto fue el del priorato de Alarcos, que posiblemente haya que relacionar con un deseo de la Orden de afianzar su posición en una villa de realengo como era Alarcos, situada en medio de su campo y a la que la corona pretendía potenciar.

Siguiendo con los factores internos, se ha aludido arriba al despegue económico del Convento central calatravo. La donación al Convento a finales del siglo XIV de una serie de derechos y propiedades por parte de los Maestres acabaron por generar una serie de rentas, que fueron utilizadas, entre otras cosas, para la adquisición de nuevas propiedades. Con ello el Convento logró hacerse con un patrimonio propio que era necesario gestionar, junto con los ingresos en especie que recibía el Convento por el mantenimiento debido del Maestre y del Clavero y el Subclavero. Para atender a la gestión de las rentas y su distribución se modificaron las funciones del Pitanciero del Convento, a la vez que se creaba los cargos conventuales de Mayordomo y Despensero para asumir parte de las funciones que antes tenía el Pitanciero.

En relación con lo expuesto arriba hay que señalar que en nuestra opinión la dotación de derechos, propiedades y rentas al Convento cabría ponerla en relación con el proceso de aristocratización ya aludido. Los Maestres y posteriormente otras dignidades y jerarquías de la Orden, hacían donaciones al Convento tanto por motivos espirituales (facilitar su salvación mediante donaciones pro anima a cambio de oraciones y misas), como de prestigio, dejando memoria suya y de su linaje a través de su recuerdo en las misas, y su escudo de armas grabado en objetos litúrgicos y en ropajes y telas donadas al Convento. Desde el siglo XV los Maestres y otros comendadores erigirían capillas en la iglesia conventual y realizarían obras en el Convento donde también dejaron la impronta de sus escudos de armas, así como en las lápidas de las capillas de la iglesia y del cementerio. Esta situación se reprodujo en algunas iglesias de los prioratos donde se enterraron comendadores y caballeros. En el caso de la iglesia del priorato de San Benito de Sevilla se fundaron varias capellanías atendidas por varios capellanes de la Orden, que vinieron a ampliar el organigrama de la estructura clerical calatrava. 
Por lo que se refiere a los factores externos, la pugna mantenida durante el reinado de Fernando III entre la Orden y las autoridades del Císter por el asunto del nombramiento del Prior de Calatrava, del Subprior y del Cillerero, va a terminar con el reconocimiento de los derechos de Morimundo al nombramiento, pero también con la desaparición de la figura del Cillerero (anulada por la del Clavero) y la potenciación de la figura del Sacristán, elevado a la categoría de dignidad con el título de Sacristán Mayor, al que se dotó de rentas y de un elevado grado de autonomía, así como de participación en las decisiones que afectaban al conjunto de la Orden a través de su asistencia frecuente a los capítulos, tanto generales como particulares. A ésta cuestión, que alteraba la estructura conventual tradicional cisterciense, hay que añadir en nuestra opinión otra alteración más de dicha estructura, con la potenciación de la figura del Obrero, que también fue elevado a la categoría de dignidad, aunque que se sustrajo de la rama clerical de la Orden al pasar a ser ostentada por un freile caballero.

Por último, de las relaciones que mantuvo la Orden con los distintos poderes diocesanos, generalmente conflictivas por motivos de jurisdicción y percepción de derechos y rentas, se va a derivar las características y atribuciones tanto de las parroquias como de los curas que las servían, con independencia de su pertenecía a la Orden.

\section{LOS FREILES CLÉRIGOS: NÚMERO E IDENTIDAD}

La menor importancia de la rama clerical de la Orden de Calatrava con respecto a la rama militar lo fue también desde un punto de vista cuantitativo. Ahora bien, saber realmente cuántos eran es una cuestión muy complicada por dos motivos: el primero por la propia importancia secundaria de los clérigos, que hace que apenas se mencionen de manera individualizada en la documentación, y el segundo porque su número fue variable en el tiempo, aunque sabemos, por lo menos, que fue aumentando. La cuestión se presenta más complicada para el período comprendido entre los inicios de la Orden y finales del siglo XIV, hasta el punto de que es imposible saber realmente cuántos eran. Podemos estar seguros, no obstante, de que entre 1164 y 1212 al menos se documentan tres freiles clérigos en el Convento central (Prior, Subprior y Cillerero), y aunque es lógico suponer que habría más no debieron alcanzar un número elevado, posiblemente menos de doce. También se documenta al menos un prior en Toledo y otro en Alarcos (desaparecido posiblemente en 1195). Se documentan también seis freiles clérigos en el convento de Alcañiz (a raíz de que en 1199 el Maestre don Martín Martínez cediera en prestimonio Alcañiz y todos los antiguos derechos de la Orden en Aragón, con el encargo expreso de reconstruir el convento con doce freiles, la mitad clérigos), y uno en Valencia con el título de prior. Todo esto supone entre 11 y 20 freiles clérigos para el conjunto de la Orden. Sabemos igualmente que a finales del siglo XIII existía un número mayor de prioratos, con lo que podemos elevar también el número de freiles clérigos. En el Convento central se documenta un número mínimo de seis freiles (incluido el Sacristán Mayor). En Aragón suponemos que como mínimo se mantendrían los seis freiles clérigos anteriormente citados, además del prior de las Casas de Valencia. En Castilla, además de los freiles del Convento de Calatrava, hay que contar con un prior en Toledo, otro en Zorita, otro 
en Santa María de los Mártires, tres en Andalucía (Sevilla, Martos y Osuna), y otros tres priores-capellanes, correspondientes al Maestre, al Comendador Mayor y al Clavero. Esto hace un mínimo de veintidós freiles clérigos. Un siglo después, debido sobre todo al aumento de prioratos y al número de freiles que debían servir obligatoriamente en el Convento central (doce según las diffiniciones de 1383), aumentó el número de freiles clérigos, documentándose al menos a treinta y seis freiles: Los doce del Convento central más el Sacristán Mayor; seis en Aragón (suponiendo que se mantuviera dicho número en Alcañiz); uno en Valencia; uno en los prioratos de Zorita y el Collado, en Guadalajara; uno en Toledo; cinco en el Campo de Calatrava (Fuencaliente, Santa María de los Mártires, Santa María de Mochuelos; Santa María de Zuqueca, y Santa María de Ureña); en Andalucía se documentan dos en Porcuna (San Benito de Porcuna y Santa María de La Coronada); uno en Sevilla; uno en Martos; $\mathrm{y}$ uno en Osuna. Hay que añadir los tres prioratos personales correspondientes al Maestre, al Comendador Mayor y al Clavero. Por último, para finales del siglo XV había vuelto a aumentar el número de freiles clérigos, al disponerse en las diffiniciones de 1468 que hubiese un mínimo de veinte freiles sirviendo el Convento central. Además, aumentó el número de prioratos, si bien desaparecieron algunos como los de Martos y Osuna, y se crearon las capellanías de Sevilla. Así, al menos se documentan cuarenta y nueve freiles clérigos: veinte en el Convento central, además del Sacristán Mayor; seis en Alcañiz y uno en Valencia; uno en Zorita y otro en El Collado; uno en Toledo; los cinco arriba citados en el Campo de Calatrava; siete en Andalucía (dos en sendos prioratos de Porcuna, un prior y dos capellanes en Sevilla, otro prior en Jaén y otro en Granada); dos capellanes de los reyes (en la Corte); un capellán mayor (¿en el Convento central?); y por último, los tres priores personales ya citados. A comienzos, del siglo XVI, la regularización masiva de clérigos diocesanos para que sirviesen las parroquias de la Orden debió de incrementar considerablemente el número de religiosos calatravos. Hay que advertir que con anterioridad a dicho momento desconocemos cuántos freiles clérigos sirvieron las parroquias calatravas, razón por la cual no hemos incluido su relación entre los freiles documentados.

En cuanto a la identidad personal de los freiles, esta cuestión lamentablemente permanece oscura excepto para el período que va de finales del siglo XIV en adelante. En el presente trabajo se ha hecho un esfuerzo por presentar una relación de los freiles clérigos que en la época medieval ocuparon cargos, ampliando en la medida de lo posible los datos ya conocidos y aportando otros nuevos. Hay que advertir que el período comprendido entre los inicios de la historia de la Orden a mediados del siglo XII y finales del siglo XIV permanece en una oscuridad casi total. Dicha oscuridad hay que atribuirla, también, a la escasa presencia de los freiles clérigos en la documentación debida al carácter secundario de los freiles clérigos dentro de la Orden, que salvo en los casos del Prior de Calatrava (y no siempre), y del Sacristán Mayor, en muy pocas ocasiones aparecen individualizados. 


\section{CATÁLOGO DE FREILES CLÉRIGOS}

Antes de seguir con la relación de freiles clérigos calatravos, se ha de advertir que en vez de seguir un orden alfabético de los mismos se ha optado por incluirlos en las siguientes categorías: Dignidades (Priores de Calatrava y Sacristanes Mayores); Convento de Calatrava; Prioratos formados (Castilla: provincia de Zorita, provincia de Toledo, provincia del Campo de Calatrava, y provincia de Andalucía); capellanes de los Reyes; prioratos personales (Maestre, Comendador Mayor y Clavero); y capellanes de Sevilla. Dentro de cada una de estas categorías se incluyen los clérigos que ocuparon los diferentes cargos siguiendo un orden cronológico. Hay que advertir, igualmente, que el criterio seguido si bien facilita la localización de los diferentes cargos, a cambio hace inevitable la reiteración de nombres en el caso de freiles que ocuparon sucesivamente distintos cargos dentro de la estructura institucional de la Orden.

\subsection{LAS DIGNIDADES DE LA ORDEN}

Priores de Calatrava

1.- Fray Raimundo de Fitero: Fundador de la Orden, gobernó esta como Abad desde 1158 hasta 1164 aproximadamente.

2.- Fray Arnaldo: Monje cisterciense francés que ejerció el cargo de Prior de Calatrava ${ }^{1}$.

3.- Fray Raimundo: Monje cisterciense de origen español, que ejerció el cargo de Prior de Calatrava ${ }^{2}$.

4.- Fray Dionisio: Monje cisterciense de origen francés que ejerció el cargo de Prior de Calatrava ${ }^{3}$.

5.- Fray Juan de Brea: Monje cisterciense de origen francés que ejerció el cargo de Prior de Calatrava ${ }^{4}$.

6.- Fray Roberto de Valois Monje cisterciense de origen francés que ejerció el cargo de Prior de Calatrava ${ }^{5}$.

7.- Fray Juan: Monje cisterciense de origen francés que ejerció el cargo de Prior de Calatrava. Se menciona en 1382, en el acuerdo sobre los diezmos de Martos y otros lugares suscrito entre la Orden y el obispado de Jaén ${ }^{6}$. Al año siguiente se encontró

${ }^{1}$ ZAPATER, M.R. Cister militante en la campaña de la Iglesia contra la sarracena furia. Historia general de las ilustrísimas, ínclitas y nobilísimas caballerías del Templo de Salmón, Calatrava, Alcántara, Avís, Montesa y Cristo. Zaragoza, 1662, p. 353.

${ }^{2} I d$.

${ }^{3} I d$.

${ }^{4} I d$.

${ }^{5} \mathrm{Id}$.

${ }^{6}$ 1382, Jaén. Ignacio J. Ortega y Cotes, I.J.; Álvarez de Baquedano, J.F. y Aranda, P. Bullarium Ordinis Militiae de Calatrava. Madrid, 1761. Ed. Facsimil. El Albir, Barcelona, 1981. (en adelante Bullarium...), pp. 7-8. Scriptura III; y, 1168, marzo, 27. Toledo. Bullarium..., pp. 216-218. Scriptura I, 
entre los asistentes al capítulo celebrado en los palacios maestrales de Almagro7. Se documenta también (ya que creemos que puede tratarse de la misma persona), en 1395 entre los asistentes al capítulo celebrado en Almagro por don Gonzalo Núñez de Guzmán ${ }^{8}$. Dos años después recibió del Maestre como donación al Convento la dehesa de El Retazo, situada en término de La Calzada y próxima al mismo, que pertenecía a la Mesa maestral. Con las rentas de esta propiedad el Convento debía mantener cinco capellanías 9 . Se documenta por último en el año de 1401 al menos en dos documentos. El primero es una carta de venta de unas casas en Almagro a favor del Convento de Calatrava. El segundo documento, datado en el monasterio de San Pedro de Gumiel con fecha 8 de agosto de 1401, recoge la venta al Convento de Calatrava de la granja de Santa María del Yezgo. El Prior de Calatrava visitaba el monasterio de San Pedro en nombre del abad de Morimundo ${ }^{10}$. Es posible que fuera el mismo Prior el que recibió del Maestre don Gonzalo Núñez de Guzmán en marzo de 1405 las penas por sacrilegio en el Campo de Calatrava, que correspondía llevar al Maestre. La carta de donación va dirigida a vos el Prior e freyles del nuestro Convento de Calatrava ${ }^{11}$, sin que conste el nombre de dicho Prior. Ocurre igual con el documento de donación de la encomienda de Belvís (situada también durante la Edad Media en término de la villa de La Calzada de Calatrava y muy cercana al Convento). La encomienda fue donada al Convento por el Maestre don Enrique de Villena en marzo de 1406, por façer bien e merçed a vos el nuestro Prior e freiles del nuestro Convento ${ }^{12}$.

8.- Fray Teobaldo: Monje cisterciense de origen francés que ejerció el cargo de Prior de Calatrava, en fecha posterior a 1406 y anterior a $1442^{13}$.

9.- Fray Juan de Sanxaris: Monje cisterciense de origen francés que ejerció el cargo de Prior de Calatrava. Se documenta a partir de 1442, en el pleito que el Prior y el Convento sostenían contra el Obrero de la Orden frey Luis Venegas sobre el derecho a pastar en las dehesas de la Obra y Belvís ${ }^{14}$. En 1444 figura entre los miembros de la Orden que dirigieron una protesta al arzobispo de Toledo don Gutierre por las coacciones sufridas para hacer elegir a don Alonso de Aragón como Maestre de Calatrava, aunque no asistió al capítulo celebrado en la capilla de San Benito de los palacios maestrales de Almagro donde se redactó el documento de dicha protesta y actuó en su nombre el Sacristán Mayor frey Alfonso ${ }^{15}$. En septiembre de 1445 los caballeros y

${ }^{7}$ 1383. Almagro. A.H.N. OO.MM. Calatrava. Libros Manuscritos. Libro Registro de Escrituras de la Orden de Calatrava. Tomo VIII. Sign. 1348-C. $n^{\circ} 12$. Fols. 42 r $^{\circ}-43$ v $^{\circ}$.

${ }^{8}$ 1395. Almagro. A.H.N. OO.MM. Calatrava. Particulares. Carpeta 466 nº 275, y no 287.

9 1397. Calatrava la Nueva. A.H.N. OO.MM. Calatrava. Libros Manuscritos. Libro Registro de Escrituras de la Orden de Calatrava. Tomo VIII. Sign. 1348-C n 26. Fols. 26 r $^{\circ}-27$ vo. También en Bullarium..., pp. 224-227. Scriptura II.

${ }^{10}$ 1401, octubre, 20. Almagro. A.H.N. OO.MM. Calatrava. Particulares. Carpeta $466 \mathrm{n}^{\circ}$ 283; y, 1401, agosto, 8. San Pedro de Gumiel de Hizán. Carpeta 466 nº 280. También en Bullarium..., pp. 229230. Scriptura $V$.

${ }^{11}$ 1405, marzo, 18. Porcuna. Bullarium..., pp. 230-231. Scriptura VII.

12 1406, marzo, 26. Calatrava la Nueva. Id. p. 231. Scriptura VIII.

${ }^{13}$ ZAPATER, ob.cit.

${ }^{14}$ 1470, octubre, 11. Almagro. Bullarium..., pp. 270-274. Scriptura II.

${ }^{15}$ 1444, diciembre, 9. Talavera de la Reina. A.H.N. OO.MM. Calatrava. Particulares. Carpeta 468 $\mathrm{n}^{\circ} 326$. 
freiles de la Orden, reunidos en Almagro, hacían juramento de fidelidad y pleito-homenaje al nuevo Maestre don Pedro Girón encabezados por el Prior del Convento ${ }^{16}$. En octubre de ese mismo año se cita a frey Juan de Sanxaris junto con frey Aparicio de Almodóvar, entonces Subprior y frey Juan Galindo, pitanciero, en representación del Convento en la compra de unas casas en Ciudad Real ${ }^{17}$.

10.- Fray Martín: Monje cisterciense de origen francés que ejerció el cargo de Prior de Calatrava entre los últimos años de de década de 1440 y $1455^{18}$.

11.- Fray Ivo de Bonarrequie: Monje cisterciense de origen francés que ejerció el cargo de Prior de Calatrava. Parece ser que fue nombrado Prior de Calatrava en 1455, según se expresa en una relación de documentos que se conservaban en el Convento de Calatrava inserta en las actas del capítulo general de $1511^{19}$. Se documenta en 1462, en la carta de donación de una huerta que hizo comendador de la Peña de Martos frey Rodrigo al Convento de Calatrava ${ }^{20}$. Dos años después se cita en la carta de notificación al papa del cambio de Osuna y Cazalla por Fuenteovejuna y Belmez ${ }^{21}$.

12.- Fray Teobaldo: Monje cisterciense de origen francés que ejerció el cargo de Prior de Calatrava entre 1465 aproximadamente y $1469^{22}$.

13.- Frey Pedro de Villanueva: Monje cisterciense de origen francés que ejerció el cargo de Prior de Calatrava. Sólo hemos encontrado una referencia este Prior, que se nombra entre los asistentes al capítulo general celebrado en Almagro en abril de 1469 para confirmar la elección como Maestre de don Rodrigo Téllez Girón ${ }^{23}$. En el capítulo celebrado en 1466 tras el entierro de don Pedro Girón en Calatrava la Nueva, en el que se eligió como Maestre a don Rodrigo Téllez Girón hijo del Maestre difunto, no estuvo presente el Prior del Convento, según se desprende de la carta que se envió al abad de Morimundo dando cuenta de tal elección, lo que quizá sea debido a que en ese momento se encontraba vacante el Priorato ${ }^{24}$.

14.- Fray Juan de Marchia: Monje cisterciense de origen francés que ejerció el cargo de Prior de Calatrava. Al igual que en el caso anterior solamente hemos encontrado una única referencia a este Prior. Éste se cita expresamente entre los asistentes al capítulo celebrado en Calatrava la Nueva en febrero de 1485, donde se aprobó la administración del maestrazgo por la corona cuando muriese don García López de Padilla $^{25}$.

15.- Fray Domingo Morelli: Monje cisterciense de origen francés que ejerció el cargo de Prior de Calatrava. Se documenta en 1501 como destinatario de una bula del papa Alejandro VI, concediendo al Prior de Calatrava facultad para llevar atributos episcopales, como la mitra y el báculo, conceder las cuatro órdenes menores, dar la

\footnotetext{
${ }^{16}$ 1445, septiembre, 25. Almagro. A.H.N. OO.MM. Calatrava. Particulares. Carpeta 468 no 329.

${ }^{17}$ 1445, octubre. Ciudad Real. A.H.N. OO.MM. Calatrava. Particulares. Carpeta 468 nº 328.

${ }^{18}$ ZAPATER, ob.cit.

19 1511, marzo, 8. Sevilla. A.H.N. OO.MM. Calatrava. Códices. Sign. 813 b. Fol. 99 vº

${ }^{20}$ 1462, julio, 2. Calatrava la Nueva. A.H.N. OO.MM. Calatrava. Particulares. Carpeta 468 n $^{\circ} 349$.

${ }^{21}$ 1464. Calatrava la Nueva. A.H.N. OO.MM. Calatrava. Particulares. Carpeta 468 no 350.

${ }^{22}$ ZAPATER, ob. cit., p. 353.

${ }^{23}$ 1469, abril, 3 y 4. Almagro. A.H.N. OO.MM. Calatrava. Particulares. Carpeta 469 no 358.

${ }^{24}$ 1466, mayo. 3. Calatrava la Nueva. A.H.N. OO.MM. Calatrava. Particulares. Carpeta 469 no 355.

25 1485, febrero, 13. Calatrava la Nueva. Bullarium..., pp. 285-290. Scriptura I.
} 
bendición solemne a los fieles y bendecir objetos litúrgicos, así como reconciliar las iglesias calatravas en que se hubiese realizado algún sacrilegio ${ }^{26}$. Sabemos que ya había fallecido en 1507 y ejercía el cargo en calidad de administrador frey Rodrigo del Moral, prior de San Benito de Jaén ${ }^{27}$.

16.- Fray Claudio Colin: Monje cisterciense de origen francés que ejerció el cargo de Prior de Calatrava. Se cita como Prior de Calatrava en las actas del capítulo general de Sevilla de 1511, en el que fue uno de los diffinidores. Además, en dicho capítulo fue nombrado visitador de la Orden de Alcántara junto con el Comendador Mayor frey Gutierre de Padilla ${ }^{28}$. Se retiró a Francia en tiempos de Carlos I ${ }^{29}$.

\section{Los Sacristanes Mayores}

1.- Frey Pedro: aparece mencionado como Sacristán Mayor en el fuero concedido a Miguelturra en $1238^{30}$.

2.- Frey Aparicio: Se cita como Sacristán Mayor en 1245, con motivo del acuerdo sobre diezmos entre el Maestre don Fernando Ordóñez y el obispo de Baeza fray Domingo ${ }^{31}$.

3.- Frey Juan Fernández: Se cita en mayo de 1245 como Sacristán Mayor en el documento de acuerdo entre el Maestre don Fernando Ordóñez y el arzobispo de Toledo sobre el pago de diezmos ${ }^{32}$. Aparece también en 1256 en el documento de acuerdo entre el Maestre don Pedro Yáñez y don Pascual obispo de Jaén ${ }^{33}$. Por último se documenta en 1257, cuando compra cuatro Evangelios glosados al abad de San Pedro de Gumiel ${ }^{34}$.

4.- Frey Fernando Yváñez: Se nombra como Sacristán Mayor en 1269 en el documento de acuerdo entre la Orden y el concejo de Toledo sobre términos ${ }^{35}$. También lo cita Rades durante el maestrazgo de don Juan González ${ }^{36}$.

5.- Frey Pedro: Aparece como Sacristán Mayor en la concordia suscrita en agosto de 1305 entre el Maestre don García López y el obispo de Córdoba don Ferrando sobre pago de diezmos ${ }^{37}$.

${ }^{26} 1501$, noviembre. 24. Roma. Id. pp. 297-299. Scriptura II.

${ }^{27}$ Diffiniciones de la Orden y Cavalleria de Calatrava conforme al Capitulo General celebrado en Madrid. Año de MDCLII, Ed. Fácsimil. Old Book. Factory. Madrid, 2003, p. 269.

${ }^{28}$ 1511, marzo, 8. Sevilla. A.H.N. OO.MM. Calatrava. Códices. Sign. 813 b.. Fols. 10 vo; 14 vo $-r^{\mathbf{o}}$; $37 \mathrm{v}^{\mathrm{o}} ; \mathrm{y} 60 \mathrm{v}^{\mathrm{o}}$.

${ }^{29}$ ZAPATER, ob. cit., pp. 329-331.

${ }^{30}$ Hevás y Buendía, I. Diccionario Histórico, Geográfico, Biográfico y Bibliográfico de la Provincia de Ciudad Real, $2^{\mathrm{a}}$ Ed. Establecimiento Tipográfico del Hospicio Provincial. Ciudad Real, 1899, p. 412.

${ }^{31}$ 1245. Bullarium..., pp. 77-79. Scriptura I.

32 1245, mayo, 7. Toledo. Id. p. 78. Scriptura II.

33 1256, mayo, 6. Mártos. Id. p. 109. Scriptura V.

${ }^{34}$ Corchado Soriano, M. Estudio Histórico-Económico-Jurídico del Campo de Calatrava. Parte II. Las Jerarquías de la Orden con rentas en el Campo de Calatrava. Instituto de Estudios Manchegos. C.S.I.C. Ciudad Real, 1983 Manuel Corchado, p. 111.

35 1269. Toledo. Bullarium..., p. 130. Scriptura VII.

${ }^{36}$ Rades y Andrada, F. Chronica de las tres Ordenes y Cavallerias de Santiago, Calatrava y Alcantara. Toledo. 1572. Edición. Facsímil. Gráficas Cervantes. Ciudad Real, 1980, Fol. 45 rº.

${ }^{37}$ 1305, agosto, 13. Córdoba. Bullarium..., pp. 202-203. Scriptura II. 
6.- Frey Sancho Fernández: Figura como Sacristán Mayor entre los asistentes al capítulo celebrado en Porcuna en $1382 .{ }^{38} \mathrm{Al}$ año siguiente asistió al capítulo celebrado en la capilla de San Benito en los palacios maestrales de Almagro ${ }^{39}$.

7.- Frey Sancho Díaz: Aparece documentado como Sacristán Mayor en 1395, en el capítulo celebrado en Almagro por el Maestre don Gonzalo Núñez de Guzmán ${ }^{40}$.

8.- Frey García: Se cita como Sacristán Mayor en 1397 en la donación de la dehesa del Retazo al Convento por el Maestre don Gonzalo Núñez de Guzmán En dicho documento junto al Sacristán aparece nombrado frey Sancho Fernández, por lo que cabe la posibilidad que se trate del Sacristán nombrado en sexto lugar, ya anciano ${ }^{41}$.

9.- Frey Alfonso Fernández: Aparece también mencionado como frey Alfonso Sacristán y como "el Sacristán viejo". Estás diferentes denominaciones y el hecho extraordinario de que ocupara su cargo de Sacristán Mayor durante más de cincuenta años puede llevar a pensar que se trataba de personas distintas, si bien se puede comprobar a través de la diversa documentación conservada que era la misma persona ${ }^{42}$. Dada la larga duración de su cargo es el Sacristán mejor documentado y del que por tanto se tienen más datos. Aparece mencionado por primera vez en el mes de octubre del año 1401 entre los asistentes al capítulo convocado por don Gonzalo Núñez de Guzmán en la villa de Pastrana ${ }^{43}$. Dos años después el mismo Maestre expide una carta a favor de frey Alfonso Sacristán para que le sean pagados los diezmos de los comensales y paniaguados de los comendadores del Campo de Calatrava ${ }^{44}$. El mismo sentido tiene la carta del papa Benedicto XIII de 1415 para que el arzobispo de Toledo no interfiera en el cobro de dichos diezmos ${ }^{45}$, y la del Maestre don Luís González de Guzmán en $1416^{46}$. En 1422 los visitadores de la Orden visitaron la Sacristanía e hicieron constar que hacía más de veinte años que el Sacristán gozaba de tal dignidad. Consta igualmente que el Sacristán no había realizado las reparaciones que los visitadores primeros le habían ordenado hacer en la casa de la dehesa de Valverde ni en el molino de la rivera del Guadiana (visita de la que no queda constancia documental más que por esta referencia), por lo que le embargaron las rentas para poder realizar dichas reparaciones y se le prohibió coger las rentas embargadas. Esta prohibición fue ignorada por frey Alfonso, lo que le supuso ser penitenciado por el Maestre don Luís de Guzmán. La penitencia le fue levantada finalmente por intercesión del co-

${ }^{38} 1382$. Porcuna. Id. p. 216. Scriptura I.

${ }^{39}$ 1383, septiembre, 8. Almagro. A.H.N. OO.MM. Calatrava. Libros manuscritos. Libro Registro de Escrituras de la Orden de Calatrava. Tomo VIII. Sign. 1.348-C. $n^{\circ} 12$.

40 1395, junio, 6. Almagro. A.H.N. OO.MM. Calatrava. Particulares. Carpeta 466 nº 275.

${ }^{41}$ 1397, febrero, 1. Calatrava la Nueva. A.H.N. OO.MM. Calatrava. Libros manuscritos. Libro Registro de Escrituras de la Orden de Calatrava. Tomo VIII. Sign. 1.348-C n 26.

${ }^{42}$ Corchado, ob. cit., p. 111. El autor cita entre los titulares de la Sacristanía Mayor a Alonso Fernández y a Frey Alfonso como dos personas distintas. También Enrique Rodríguez-PicaveA, E. ("Prosopografía de la Orden de Calatrava en Castilla: Primera mitad del siglo XV" en, Meridies. Revista de Historia Medieval VII (2005), pp. 201-244), distingue entre frey Alfonso Fernández y Frey Alfonso de La Calzada.

${ }_{43}^{43}$ 1401, octubre, 18. Pastrana. A.H.N. OO.MM. Calatrava. Particulares. Carpeta 466 nº 282.

${ }^{44}$ 1403, julio, 29. Almagro. A.H.N. OO.MM. Calatrava. Particulares. Carpeta 466 nº 286.

45 1415, Diciembre, 16. San Mateo. Bullarium..., pp. 234-235. Scriptura X.

46 1416, junio, 17. Almagro. A.H.N. OO.MM. Calatrava. Particulares. Carpeta 466 nº 291. 
mendador de Otos don Juan Ramírez de Guzmán y de don Vasco de Guzmán, arcediano de Toledo ${ }^{47}$. En 1442 actuó como juez, junto con el Clavero don Fernando de Padilla, en el pleito que el Prior y los freiles del Convento sostenían con el Obrero frey Luís Venegas sobre el pacer las hierbas de las dehesas de la Obra y de Belvís, según consta en un traslado de 11 de octubre de $1470^{48}$. Dos años después se vería envuelto en los sucesos que rodearon la elección de don Alonso de Aragón como maestre de Calatrava. Su nombre aparece en la protesta que frey Pedro de Ulloa presentó ante el arzobispo de Toledo por la violencia de tal elección ${ }^{49}$. Al año siguiente figura entre los freiles y caballeros que prestaron pleito-homenaje a don Pedro Girón en los palacios maestrales de Almagro ${ }^{50}$. Finalmente se documenta por última vez en una carta fechada en Magán a dos de abril 1451, por la que el Maestre don Pedro Girón concede la Sacristanía a frey Bartolomé de Almodóvar. En la carta se explican los motivos de la destitución de frey Alfonso, que se dedicaba a robar objetos sagrados de la iglesia del Convento para venderlos en Ciudad Real y usaba además la casa de la dehesa de Valverde para acoger y hacer tratos con otros ladrones. Don Pedro Girón lo acusó también de desobediencia, por lo que es posible que hubiera sido castigado o al menos advertido por estos delitos con anterioridad ${ }^{51}$.

10.- Frey Bartolomé de Almodóvar: Fue primero Prior de San Benito de Jaén. Ejerció el cargo de Sacristán Mayor a partir de $1451^{52}$. En 1459 fue nombrado visitador del Campo de Calatrava junto con el comendador de las Guadalherzas ${ }^{53}$. También realizó la visita de 1463, ésta vez en compañía del comendador de Montanchuelos frey Alfonso de Ávila. En 1464 aparece mencionado en la carta por la que se notificó al papa el cambio de Fuenteovejuna y Belmez por Osuna y Cazalla ${ }^{54}$, y dos años después asistió al capítulo celebrado en Almagro para debatir sobre la elección del Maestre de don Rodrigo Téllez Girón hecha en Villarrubia tras la muerte de su padre don Pedro Girón. También asistió al capítulo general celebrado inmediatamente después en el Convento de Calatrava para hacer efectiva dicha elección ${ }^{55}$. En el mes de agosto del mismo año de 1466 el Maestre expidió una carta en favor del Sacristán para que le fuesen pagados los diezmos de los comensales y paniaguados del Campo de Calatrava ${ }^{56}$. En abril de 1469 asistió al capítulo celebrado en los palacios maestrales de Almagro para acatar la bula de Pablo II, que nombraba a don Rodrigo Téllez Girón Maestre-administrador de la Orden de Calatrava y a su tío don Juan Pacheco coadjutor en el maestrazgo hasta que don Rodrigo cumpliera los veinticinco años de

${ }^{47}$ 1422, septiembre 9 y 1423, enero. 9 La Sacristanía. A.H.N. OO.MM. Calatrava. Libros Manuscritos. Sign. 1.412-C.

${ }^{48}$ 1470, octubre, 11. Almagro. Bullarium..., pp. 270-274. Scriptura II.

49 1444, diciembre, 9. Talavera de la Reina. A.H.N. OO.MM. Calatrava. Particulares. Carpeta 468 $\mathrm{n}^{\circ} 326$.

50 1445, septiembre, 25. Almagro. A.H.N. OO.MM. Calatrava. Particulares. Carpeta 468 no 329.

${ }^{51}$ 1451, abril, 2. Magán. A.H.N. OO.MM. Calatrava. Particulares. Carpeta 468 nº 338.

${ }^{5} \mathrm{Id}$.

${ }^{53}$ 1459. A.H.N. OO.MM. Calatrava. Visitas. Legajo. 6.109 n ${ }^{\circ} 57.1459$.

${ }^{54}$ 1464. Calatrava la Nueva. A.H.N. OO.MM. Calatrava. Particulares. Carpeta 469 nº 366.

55 1466, mayo, 3. Calatrava la Nueva. A.H.N. OO.MM. Calatrava. Particulares. Carpeta 469 no 355.

${ }^{56}$ 1466. A.H.N. OO.MM. Calatrava. Particulares. Carpeta 469. Sin Número. 
edad $^{57}$. Se menciona también entre los asistentes al capítulo celebrado en Calatrava la Nueva en febrero de 1485, por el que se aprobó la incorporación de la administración del maestrazgo de la Orden a la corona, aunque figura sólo como "el Sacristán Mayor" ${ }^{\prime 2}$. En diciembre del mismo año el Maestre le concedió sus derechos sobre la villa de La Calzada como compensación por la pérdida de los diezmos de comensales y paniaguados, que don Rodrigo Téllez Girón había cambiado al arzobispo de Toledo en 1480 por el terzuelo de la villa de Almagro ${ }^{59}$. Finalmente aparece citado en 1488, en el documento por el que don Garcí López de Padilla acensó al concejo de la villa de Torralba las dehesas de El Campo y El Verdugal ${ }^{60}$.

11.- Frey Juan de Almagro: Ejerció primero como prior o capellán de los maestres don Pedro Girón ${ }^{61}$, y de su hijo don Rodrigo Téllez ${ }^{62}$. En 1485 lo encontramos en el Convento de Calatrava con el cargo de Cantor del Convento, según consta en el documento citado con anterioridad por el que el capítulo autorizó la incorporación del maestrazgo a la corona y en el que frey Juan ejerció como secretario del mismo ${ }^{63}$. En 1488 se documenta como prior de San Benito de Sevilla ${ }^{64}$, y ya en 1493 aparece por primera vez como Sacristán del Convento. Realizó las visitas al Campo de Calatrava en $1493^{65}$ y $1495^{66}$.

12.- Frey Pedro de Troya: Se cita en 1492 como prior de las Casas de Sevilla ${ }^{67}$, donde continuaba en 1502 cuando fue visitador general junto al comendador de Malagón frey Pedro de Aguayo. Consta además, que ejercía el cargo de capellán de los Reyes $^{68}$. En 1509 se menciona como Sacristán Mayor ${ }^{69}$.

\subsection{CONVENTO DE CALATRAVA}

\section{SubPriores de CALATrava}

1.- Frey Pedro de Almonace: Se cita como Subprior en 1438, en el documento de donación de unas casas en Ciudad Real que hizo el comendador frey Sancho Sánchez de Ávila ${ }^{70}$.

${ }^{57}$ 1469, abril, 3 y 4. Almagro. A.H.N. OO.MM. Calatrava. Particulares. Carpeta 469 nº 358.

${ }_{58}$ 1485, febrero, 13. Calatava la Nueva. Bullarium..., pp. 285-290. Scriptura I.

59 1485, diciembre, 20. Jaén. Id. pp. 477-479. Scriptura XXVIII.

${ }^{60}$ 1488, julio, 5. Almagro. A.H.N. OO.MM. Calatrava. Particulares. Carpeta 469 nº 368.

${ }^{61}$ 1466, abril, 28. Villarrubia de los Ojos. A.H.N. OO.MM. Calatrava. Particulares. Carpeta 469 n $^{\circ}$ 366, y A.H.N. Osuna. Legajo 1, no 19; ViÑA BRITo, A. "El Testamento de Don Pedro Girón”, en, Anuario de Estudios Medievales $\mathrm{n}^{\circ} 19$ (1988), pp. 191-216. Consta que el Maestre legó 5.000 maravedís “...a frey Iohan mi prior..."

${ }^{62}$ A.H.N. OO.MM. Calatrava. Particulares. Carpeta 469 n 358.

${ }^{63} 1485$, febrero, 13. Calatrava la Nueva. Bullarium..., pp. 285-290. Scriptura I,

${ }^{64}$ 1488, julio, 5. Almagro. A.H.N. OO.MM. Calatrava. Particulares. Carpeta 469 no 368.

${ }^{65}$ 1493, junio, 1. La Calzada. A.H.N. OO.MM. Consejo. Calatrava. Visitas. Legajo. 6.109 n 22.

${ }^{66}$ 1495, julio, 27. La Calzada. A.H.N. OO.MM. Consejo. Calatrava. Visitas. Legajo. 6.109 no 27.

${ }^{67}$ 1492, octubre, 4. Sevilla. A.H.N. OO.MM. Consejo. Calatrava. Visitas. Legajo $6109 \mathrm{n}^{\circ} 18$. Fol. 5 ro

${ }^{68}$ 1502, febrero, 28. La Calzada. A.H.N. OO.MM. Consejo. Calatrava. Visitas. Legajo. 6.075, n ${ }^{\circ} 28$.

${ }^{69}$ 1510, marzo. La Calzada. A.H.N. OO.MM. Consejo. Calatrava. Visitas. Legajo. 6.076, no 39.

${ }^{70}$ 1438, junio, 4. Calatrava la Nueva. A.H.N. OO.MM. Calatrava. Particulares. Carpeta 467 no 316. 
2.- Frey Gonzalo: Se cita como Subprior entre los asistentes al capítulo general celebrado en Almagro en septiembre de $1443^{71}$. Con anterioridad es posible que se trate del mismo personaje que aparece como confirmante de la sentencia en el conflicto entre el Convento y el Obrero de Calatrava por el pasto de las dehesas de la Obra y Belvís ${ }^{72}$.

3.- Frey Aparicio de Almodóvar: Se cita en 1443 como freile clérigo ${ }^{73}$. Como Subprior se cita entre 1445 y $1448^{74}$. Posteriormente se cita como prior de Jaén entre 1462 y $1469^{75}$.

4.- Frey Juan de Belmonte: Se cita como Subprior del Convento en $1462^{76}$.

5.- Frey Gonzalo Díaz de Haro: Se cita como Subprior entre 1494, cuando le fue encargado junto con el Prior del Convento que visitase el convento de monjas de San Felices de Amaya para proceder a su reforma y en 1502 cuando realizó junto con el comendador frey Sancho de Lendoño la visita a la Orden de Montesa ${ }^{77}$.

6.- Frey Alonso de Valenzuela: Se cita como Subprior en 1511, en el capítulo general reunido en Sevilla ${ }^{78}$.

\section{Pitancieros}

1.- Frey Alfonso: Se cita como Pitanciero en 1401, en la carta de venta de unas casas en la plaza de Almagro al Convento de Calatrava ${ }^{79}$.

2.- Frey Gonzalo: Se cita como Pitanciero en $1438^{80}$.

3.- Frey Antonio de Almodóvar: Se cita como Pitanciero entre los asistentes al capítulo general celebrado en $1443^{81}$.

4.- Frey Juan Galindo: En 1443 se nombra como prior de San Benito de Porcuna ${ }^{82}$. Se documenta como Pitanciero del Convento en 1445 y $1448^{83}$. Más tarde pasaría a

71 1443, septiembre. Almagro. A.H.N. OO.MM. Calatrava. Particulares. Carpeta 467 no 321 bis.

72 1470, octubre, 11. A.H.N. OO.MM. Calatrava. Particulares. Carpeta 469 no 360 . (traslado del original de 1442, diciembre, 15. Almagro); Bullarium... ob. cit., pp. 270-274. Scriptura II; RodríGUEZPicaVeA, ob. cit., p. 22.

73 1443, septiembre. Almagro. A.H.N. OO.MM. Calatrava. Particulares. Carpeta 467 nº 321 bis.

74 1445, octubre, 24. La Calçada. A.H.N. OO.MM. Calatrava. Particulares. Carpeta 468 n³28; y 1448, septiembre, 11.Argamasilla.

75 1462, marzo, 22. Porcuna. A.H.N. OO.MM. Calatrava. Particulares. Carpeta 469 no 352; 1463, junio, 14. Jaén. A.H.N. OO.MM. Calatrava. Visitas. Legajo 6109 nº 12. Fols. 175 ro 178 v $^{\circ}$; 1464, marzo, 20. Porcuna. A.H.N. Osuna. Leg. 2 n 1; y, 1469, abril, 3 y 4. Almagro. A.H.N. OO.MM. Calatrava. Particulares. Carpeta 469 n 358.

76 1462, julio, 2. A.H.N. OO.MM. Calatrava. Particulares. Carpeta 468 nº 350.

77 1502. R.A.H. Col. Salazar. Sign I-5². Fol. 17 vo; y, 1494, septiembre, 29. Madrid A.G.S. CCA, CED, 3-2, 61, 2; 1511, marzo, 8. Sevilla. A.H.N. OO.MM. Calatrava. Códices. Sign. 813 b. Fol. 60 ro.

78 1511, marzo, 8. Sevilla. A.H.N. OO.MM. Calatrava. Códices. Sign. 813 b. Fol. 60 ro

79 1401, octubre, 20. Almagro. A.H.N. OO.MM. Calatrava. Particulares. Carpeta 466 n 283.

${ }^{80}$ 1438, junio, 13. Ciudad Real. A.H.N. OO.MM. Calatrava. Particulares. Carpeta 467 n 317 . V

${ }^{81}$ 1443, septiembre. Almagro. A.H.N. OO.MM. Calatrava. Particulares. Carpeta 467 no 321 bis.

${ }^{82} \mathrm{Id}$.

83 1445, octubre, 21, La Calzada. A.H.N. OO.MM. Calatrava. Particulares. Carpeta 468 nº 328. 
ocupar el priorato de Santa María de Zuqueca, en el que se documenta entre 1459 y $1469^{84}$.

5.- Frey Alonso del Moral: Ejerció el cargo de Pitanciero al menos entre 1459, año en que se cita en la visita efectuada al Convento por el Sacristán frey Bartolomé de Almodóvar y el comendador de Guadalherza frey Juan Morán, y $1478^{85}$. Fuer enterrado en el cementerio de los Mártires de Calatrava la Nueva cuando falleció el 25 de julio de 1479. En 1468 el abad de Morimundo Guillermo II, en las diffiniciones que dio a Calatrava, ordenó al Clavero que junto con el Prior, el Sacristán Mayor y el Obrero, investigaran las costumbres y la vida del Pitanciero, el cual además de disfrutar de un priorato participaba de las distribuciones como un conventual más, a pesar de que también gozaba de un salario por su oficio de Pitanciero, que no ejercía, lo mismo que ocurría con el Enfermero. Parece, además, que tenían ciertos bienes o rentas arrendados a seglares ${ }^{86}$. Todo esto estaba prohibido por la normativa de la Orden, produciéndose una clara situación de irregularidad. Por la lauda sepulcral de frey Alonso sabemos, además de la fecha de su muerte, que el priorato en cuestión era el de Córdoba ${ }^{87}$, lo que o bien se trata de un error, pues es la única mención a dicho priorato que aparece en la documentación calatrava (Rades tampoco lo menciona en su crónica), o abundando en la irregularidad se creó este priorato sólo para frey Alonso.

6.- Frey Rodrigo de Pegalajara: Se cita como freile conventual en 1462 y $1466^{88}$, y como Pitanciero del Convento entre 1492 y $1495^{89}$.

7.- Frey Juan de Bolaños: Se nombra como prior de El Collado en $1466^{90}$. Tres años después ostentaba el cargo de prior o capellán del Comendador Mayor ${ }^{91}$. Ejerció el cargo de Pitanciero al menos entre 1502 y $1510^{92}$.

\section{CANTORES}

\section{1.- Frey Antón: Se cita como Cantor en $1438^{93}$.}

${ }^{84}$ 1469, abril, 3 y 4. Almagro. A.H.N. OO.MM. Calatrava. Particulares. Carpeta 469 no 358.

${ }^{85}$ 1459, febrero, 17. Calatrava la Nueva. A.H.N. OO.MM. Calatrava. Visitas. Legajo $6109 \mathrm{n}^{\mathrm{o}} 2$. Fols, 39 r $^{\circ}-45$ ro ; A.H.N. OO.MM. Calatrava. Particulares. Carpeta 468 n $^{\circ} 350 ; 1462$, julio, 2. Calatrava la Nueva; A.H.N. OO.MM. Calatrava. Particulares. Carpeta $468 \mathrm{n}^{\circ}$ 350; 1466, mayo. Calatrava la Nueva A.H.N. OO.MM. Calatrava. Particulares. Carpeta 469 n 358 ; y, 1478, mayo, 16. Almagro y mayo 18 y 20. Ciudad Real. Carpeta 469 n $^{\circ} 366$.

${ }^{86} \mathrm{O}^{\prime}$ Callagham, J.F."Diffiniciones of the Order of Calatrava Enacted by Abbot William II of Morimond, April, 2, 1468”, en Traditio núm 14 (1958), pp. 231-268.

${ }^{87}$ 1561, enero, 1. Calatrava la Nueva Copia de varias Inscripciones y epitafios que se hallan en la iglesia y capillas del convento de Calatrava, entre ellas, las correspondientes al sepulcro de Pedro Girón, maestre de la orden de Calatrava [I señor de Ureña].Osuna. C. 2 D. 34.

${ }^{88} 1462$, julio, 2. Calatrava la Nueva (¿?); A.H.N. OO.MM. Calatrava. Particulares. Carpeta 468 n $^{\circ}$ 350; y 1466, mayo. Calatrava la Nueva. Carpeta 469 n 358.

89 1495, julio, 25. Convento de Calatrava. A.H.N. OO.MM. Consejo. Calatrava. Visitas. Legajo 109 $\mathrm{n}^{\circ} 29$. Fols. $171 \mathrm{r}^{\mathrm{o}}-180 \mathrm{v}^{\mathrm{o}}$.

${ }_{90}$ 1466. mayo. Calatrava la Nueva. A.H.N. OO.MM. Calatrava. Particulares. Carpeta 469 n $^{\circ} 355$. 1466. mayo. Calatrava la Nueva.

${ }^{91}$ 1469, abril, 3 y 4. Almagro. A.H.N. OO.MM. Calatrava. Particulares. Carpeta 469 no 558.

92 1511, marzo, 8. Sevilla. A.H.N. OO.MM. Calatrava. Códices. Sign. 813 b. Fol. 71 ro.

${ }_{93}$ 1438, junio, 4. Calatrava la Nueva. A.H.N. OO.MM. Calatrava. Particulares. Carpeta 467 no 316. 
2.- Frey Bartolomé: Se nombra ejerciendo el cargo de Cantor en $1442^{94}$.

3.- Frey Fernando de Valdepeñas: Se cita como Cantor del Convento entre 1443 y $1466^{95}$.

4.- Frey Juan de Almagro: En 1472 se cita como freile conventual ${ }^{96}$. Entre 1462 y 1469 se documenta como prior o capellán del Maestre ${ }^{97}$. Se cita como Cantor en el capítulo general de 1485 , en el que ejerció de secretario ${ }^{98}$. Posteriormente ostentó el cargo de Prior de San Benito de Sevilla ${ }^{99}$, y en 1489 el de Sacristán Mayor ${ }^{100}$.

\section{Capellanes del Convento}

1.- Frey Gonzalo: Se cita como Capellán de los freiles del Convento en 1434 $4^{101}$.

2.- Frey Martín de Almodóvar: Se cita como Capellán Mayor de la Orden de Calatrava en 1495, cuando fue enviado por los Reyes al Convento de la Orden de Alcántara con el encargo de proceder a su reforma ${ }^{102}$.

\section{ENFERMEROS/HOSPEDEROS}

1.- Frey Miguel: Se cita como enfermero en $1434^{103}$.

2.- Frey Francisco: Se cita como Enfermero del Convento en 1459, aunque consta que ejercía el cargo desde tiempo atrás ${ }^{104}$.

3.- Frey Juan Cañizares: Se nombra como Enfermero entre 1462 y $1466^{105}$.

\section{MAYORDOMOS}

1.- Frey Álonso de Almodóvar: Se cita como freile presbítero en 1443. En septiembre de ese mismo año se cita como mayordomo del Convento ${ }^{106}$.

\footnotetext{
${ }^{94}$ 1470, octubre, 11. Almagro. A.H.N. OO.MM. Calatrava. Particulares. Carpeta 469 nº360; Bullarium... ob. cit., pp. 270-274. Scriptura II.

${ }_{95}$ 1443, septiembre. Almagro. A.H.N. OO.MM. Calatrava. Particulares. Carpeta 467 no 321 bis; 1462, julio, 2. Calatrava la Nueva. Carpeta 468 n $^{\circ} 350$; Carpeta 469 n$^{\circ} 358$. 1466, mayo. Calatrava la Nueva.

${ }^{96}$ 1472, noviembre, 28. Almagro. A.H.N. OO.MM. Calatrava. Particulares. Carpeta 469 no 361.

${ }^{97}$ A.H.N. OO.MM. Calatrava. Particulares. Carpeta 469 n 352.1462 , marzo, 22. Porcuna; y, 1469 , abril, 3 y 4 . Almagro. ${ }^{\circ} 358$.

${ }_{98}$ 1485, febrero, 13. Calatrava la Nueva. Bullarium..., ob. cit., Scriptura I, pp. 285-290.

${ }^{99}$ 1488, julio, 5. Almagro. A.H.N. OO.MM. Calatrava. Particulares. Carpeta 469 n 368.

100 1489, agosto, 3. Aldea del Rey. A.H.N. OO.MM. Calatrava. Libros manuscritos. Libro Registro de Escrituras de la Orden de Calatrava. Tomo VIII. Sign. 1348-C. Fols. 125 r $^{\mathrm{o}}$ y ss.

${ }^{101}$ Rodríguez-PicaVea, ob. cit., p. 221.

102 1495, octubre, 20. Tarazona. A.G.S. CCA, CED, 1, 257,1.

${ }^{103}$ Rodríguez-PicAVEA, ob. cit., p. 228.

${ }^{104}$ 1459, febrero, 17. Calatrava la Nueva. A.H.N. OO.MM. Calatrava. Visitas. Legajo 6109 n $^{\circ} 2$. Fols, $39 \mathrm{r}^{\mathrm{O}}-45 \mathrm{r}^{\mathrm{o}}$.

${ }^{105}$ 1462, julio, 2. Calatrava la Nueva. A.H.N. OO.MM. Calatrava. Particulares. Carpeta $468 \mathrm{n}^{\circ} 350$; y 1466, mayo. Calatrava la Nueva. Carpeta 469 n 358.

106 1443, noviembre, 2. A.H.N. OO.MM. Calatrava. Particulares. Carpeta 499 nº 127; RAH. Col. Salazar. Sign. I-38, Fols. 99 ro-100 ro; RodRíGUEZ-PiCAVEA, ob. cit., pp. 204-205.
} 
2.- Frey Alonso de Ocaña: Ejerció el cargo de Mayordomo al menos en 1492 y 1493.

3.- Frey Pascual: Se cita como mayordomo del Convento en el libro de visitas de $1495^{107}$.

\section{SUBSACRISTANES}

1.- Frey Alfonso de Jaén: Se cita como Subsacristán en $1462^{108}$. En 1466 se cita como prior o rector de la iglesia parroquial de San Bartolomé de Almagro ${ }^{109}$. Por último se cita como capellán de Sevilla en las actas del capítulo general de 1511, aunque ya había fallecido ${ }^{110}$.

$2^{\circ}$.- Frey Hernando de Almodóvar: Era Subsacristán en $1495^{111}$.

\subsection{PRIORATOS FORMADOS}

\section{PRIORES DE ZORITA}

1.- Frey Juan: Se cita como prior de Zorita en 1433, en el capítulo general celebrado en Calatrava la Nueva donde el abad de Morimundo Guido III dio diffiniciones a la Orden ${ }^{112}$.

2.- Frey Pedro de Almonecar: Se documenta en la visita al priorato de 1491 como prior que fue, aunque no se concreta cuándo.

3.- Frey Alfonso de Almagro: Se nombra como prior de Zorita en $1489^{113}$. Con anterioridad, se cita entre 1462 y 1466 como prior de San Benito de Sevilla ${ }^{114}$, documentándose en 1469 ya otro prior ${ }^{115}$.

4.- Frey Alonso de Villafranca: Se menciona como prior de Zorita y de El Collado entre 1491 y $1502^{116}$.

107 1495, julio, 25. Convento de Calatrava. A.H.N. OO.MM. Consejo. Calatrava. Visitas. Legajo 109 $\mathrm{n}^{\mathrm{o}} 29$. Fols. $171 \mathrm{r}^{\mathrm{o}}-180 \mathrm{v}^{\mathrm{o}}$.

${ }^{108}$ 1462, julio, 2. Calatrava la Nueva. A.H.N. OO.MM. Calatrava. Particulares. Carpeta 468 no 350

109 1466, mayo. Calatrava la Nueva. A.H.N. OO.MM. Calatrava. Particulares. Carpeta 469 no 358.

110 1511, marzo, 8. Sevilla. A.H.N. OO.MM. Calatrava. Códices. Sign. 813 b. Fol. 75 ro .

111 1495, julio, 25. Convento de Calatrava. A.H.N. OO.MM. Consejo. Calatrava. Visitas. Legajo 109 $\mathrm{n}^{\circ}$ 29. Fol. $177 \mathrm{r}^{\mathrm{o}}$.

112 Rodríguez-Picavea, ob. cit., p. 224.

113 1489, agosto, 3. Aldea del Rey. A.H.N. OO.MM. Calatrava. Libros manuscritos. Libro Registro de Escrituras de la Orden de Calatrava. Tomo VIII. Sign. 1348-C. Fols. 125 r $^{\mathrm{o}}$ y ss.

114 1462, marzo 22. Porcuna. A.H.N. OO.MM. Calatrava. Particulares. Carpeta 469 n 352.; nº 366. 1464; y, no 355. 1466, mayo. Calatrava la Nueva.

115 1469, abril, 3 y 4. Almagro. A.H.N. OO.MM. Calatrava. Particulares. Carpeta 469 no 358.

116 1491, septiembre, 22. Zorita. A.H.N. OO.MM. Consejo. Calatrava. Visitas. Legajo 6109 n $^{\circ} 17$. Fols, $272 \mathrm{r}^{\mathrm{o}}-275 \mathrm{v}^{\mathrm{o}} ; 1494$, octubre, 20. Zorita $\mathrm{n}^{\mathrm{o}} 25$. Fols. $19 \mathrm{r}^{\mathrm{o}}-22 \mathrm{v}^{\mathrm{o}} ; \mathrm{y}, 1502$, mayo, 29. Alvalate. Legajo $6110 \mathrm{n}^{\circ} 6$. Fols, $208 \mathrm{r}^{\mathrm{o}}-210 \mathrm{v}^{\mathrm{o}}$. 


\section{Priores de El Collado}

1.- Frey Juan de Bolaños: Se cita como prior de El Collado en $1466^{117}$. Tres años después es citado en la documentación como prior o capellán del Comendador Mayor ${ }^{118}$. Posteriormente ejerció el cargo de Pitanciero del Convento al menos entre 1502 y $1510^{119}$.

2.- Frey Alonso de Villafranca: Se menciona como prior de El Collado y de Zorita entre 1491 y $1502^{120}$.

\section{Priores de Santa Fe-San Benito de Toledo}

1.- Frey Pedro: Se cita en 1431 como prior de las Casas de Toledo ${ }^{121}$.

2.- Frey Bartolomé de Almagro: Entre 1460 y 1464 era prior del Maestre ${ }^{122}$. En 1466 ya era titular de Santa Fe de Toledo ${ }^{123}$.

3.- Frey Gil de Molina: Se cita como prior de Toledo en $1489^{124}$. En 1493 era prior de las Casas de Valencia ${ }^{125}$.

4.- Frey Alonso de Arroyo: Se cita como prior en $1493^{126}$. Dos años después era prior de Alcañiz, en Aragón ${ }^{127}$.

5.- Frey Bernabé: Se cita en el libro de visitas del año de 1500 al priorato de San Benito de Toledo ${ }^{128}$. En 1511 consta que ya había fallecido ${ }^{129}$.

6.- Frey Bernardino: debió sustituir al anterior. Se cita como prior en el capítulo general de $1511^{130}$.

\section{Priores de Santa María de Fuencaliente}

1.- Frey Benito Sánchez: Se documenta en 1369 como receptor de la carta puebla de la villa otorgada por don Pedro Muñíz de Godoy ${ }^{131}$.

\footnotetext{
117 1466. mayo. Calatrava la Nueva. A.H.N. OO.MM. Calatrava. Particulares. Carpeta $469 \mathrm{n}^{\circ} 355$.

118 1469, abril, 3 y 4. Almagro. A.H.N. OO.MM. Calatrava. Particulares. Carpeta 469 no 558.

119 1511, marzo, 8. Sevilla. A.H.N. OO.MM. Calatrava. Códices. Sign. 813 b. Fol. 71 ro

${ }_{120}$ 1491, septiembre, 22. Zorita. A.H.N. OO.MM. Consejo. Calatrava. Visitas. Legajo 6109 n $^{\circ} 17$. Fols, $272 \mathrm{r}^{\mathrm{o}}-275 \mathrm{v}^{\mathrm{o}}$; y, 1502, mayo, 29. Alvalate. Legajo $6110 \mathrm{n}^{\circ}$ 6. Fols. $208 \mathrm{r}^{\mathrm{o}}-210 \mathrm{v}^{\mathrm{o}}$.

121 1431. R.A.H. Col. Salazar Sign. M-130. Fols. 61 vo $-63 v^{\circ}$.

122 1460, enero, 1. Valdepeñas A.H.N. Osuna. Legajo $41 \mathrm{n}^{\mathrm{o}} 1$; y, 1464, marzo, 20. Porcuna. A.H.N. Osuna. Legajo $2 \mathrm{n}^{\circ} 1$.

${ }^{123}$ 1466, mayo. Calatrava la Nueva. A.H.N. OO.MM. Calatrava. Particulares. Carpèta 469 no 355.

124 1489, enero, 1. Almagro. A.H.N. OO.MM. Calatrava. Particulares. Carpeta 469 nº 370.

${ }^{125}$ 1493, febrero, 22. Barcelona. A.G.S. Sign. CCA, CED, 3-2,1, 4.

126 1493, mayo, 19. Toledo. A.H.N. OO.MM. Consejo. Calatrava. Visitas. Legajo 6109 no 24. Fols. $251 \mathrm{r}^{\mathrm{o}}-252 \mathrm{v}^{\mathrm{o}}$.

127 1495, marzo, 22. Madrid. A.G.S. Sign. CCA-CED. 3-2-66-2.

${ }_{128}$ 1500, febrero, 1. Toledo. A.H.N. OO. MM. Consejo. Calatrava. Visitas. Legajo 6109 no 58 . Fols. $50 \mathrm{r}^{\mathrm{o}}-52 \mathrm{v}^{\mathrm{o}}$.

${ }^{129}$ 1511, marzo, 8. Sevilla. A.H.N. OO.MM. Calatrava. Códices. Sign. 813 bFol. 18 ro

${ }^{130}$ Id. Fol. $68 \mathrm{r}^{\mathrm{o}}$.

131 1369, junio, 25. Porcuna. Bullarium ... pp. 422-427. Scriptura IX.
} 
2.- Frey Alfonso: Se documenta al frente del priorato de Fuencaliente entre 1417 y $1423^{132}$.

3.- Frey Juan: Se cita como prior de Santa María de la Fuencaliente entre 1433 y $1434^{133}$.

4.- Frey Fernando de Montoro: Se cita como prior de Fuencaliente en el capítulo celebrado en $1443^{134}$. Posteriormente se cita como prior de Santa María de La Coronada de Porcuna entre 1459 y $1466^{135}$.

5.- Frey Pedro de Almagro: Se cita como prior de Fuencaliente al menos entre 1459 y $1469^{136}$.

6.- Frey Martín de Ureña: Entre 1462 y 1466 se documenta como freile conventual ${ }^{137}$. Se cita en 1484 como prior de Fuencaliente ${ }^{138}$.

7.- Frey Juan de Molina: Se nombra como prior de Fuencaliente entre 1495 y $1500^{139}$.

8.- Frey Hernando Guijo: Se cita en el capítulo general que la Orden celebró en Sevilla en marzo de $1511^{140}$.

\section{Priores de Santa María de Zuqueca}

1.- Frey Juan Galindo: Se cita como prior de San Benito de Porcuna en 1443. Se documenta en 1445 y 1448 como pitanciero del Convento ${ }^{141}$, y en 1459 era ya prior de Santa María de Zuqueca. Se nombra por última vez en $1469^{142}$.

2.- Frey Gonzalo de Puertollano: Fue prior de Zuqueca por lo menos entre 1500 y 1504. Tenía también a su cargo la ermita de San Benito de Almagro, situada en el interior de los palacios maestrales.

3.- Frey Pascual de Bolaños: Se cita en 1511 como uno de los priores que los definidores habían nombrado para recoger las cédulas de las confesiones de comendadores y caballeros. Así mismo fue nombrado visitador de las Orden para las tierras comprendidas dentro del reino de Castilla ${ }^{143}$.

${ }^{132} 1417$, diciembre. Almagro. A.H.N. OO.MM. Calatrava. Particulares. Carpeta 467 no 284; y 1423, enero. Fuencaliente. A.H.N. OO.MM. Calatrava. Libros Manuscritos. Sign. 1.412-C. Fol. 17 vo; RodRÍGUeZ-PICAVEA, ob. cit., p. 203.

${ }^{133}$ Rodríguez-PicaveA, ob. cit., p. 224.

${ }^{134}$ Id. p. 229.

135 1459, marzo, 26. Porcuna. A.H.N. OO.MM. Calatrava. Visitas. Legajo 6109 no 8. Fols, 251 r $^{\circ}-$ 253 ro $;$ y, 1466, mayo. Calatrava la Nueva. A.H.N. OO.MM. Calatrava. Particulares. Carpeta 469 n $^{\circ} 355$.

136 1459, febrero, 17. Calatrava la Nueva. A.H.N. OO.MM. Calatrava. Visitas. Legajo $6109 \mathrm{n}^{\circ} 2$. Fols, 39 r $^{\circ}-5$ ro ; 1466, mayo. Calatrava la Nueva. A.H.N. OO.MM. Calatrava. Particulares. Carpeta 469 $\mathrm{n}^{\circ} 355 ; \mathrm{y}, 1469$, abril, 3 y 4. Almagro. A.H.N. OO.MM. Calatrava. Particulares. Carpeta $469 \mathrm{n}^{\circ} 358$.

${ }_{137}$ 1466, mayo. Calatrava la Nueva. A.H.N. OO.MM. Calatrava. Particulares. Carpeta $468 \mathrm{n}^{\circ} 350$. 1462, julio, 12. Calatrava la Nueva, y Carpeta $469 \mathrm{n}^{\circ} 355$.

${ }_{138} 1484$, noviembre, 10. Argamasilla de Calatrava. Bullarium... pp. 422-427. Scriptura IX.

${ }^{139}$ Id. y 1500, marzo. 10. Fuencaliente. A.H.N. OO.MM. Consejo. Calatrava. Visitas. 6109 n $^{\circ} 50$ Fols. $132 \mathrm{r}^{\mathrm{o}}-134 \mathrm{v}^{\mathrm{o}}$.

140 1511, marzo, 8. Sevilla. A.H.N. OO.MM. Calatrava. Códices. Sign. 813 b.

${ }^{141}$ 1445, octubre, 21, La Calzada. A.H.N. OO.MM. Calatrava. Particulares. Carpeta 468 n 328.

142 1469, abril, 3 y 4. Almagro.A.H.N. OO.MM. Calatrava. Particulares. Carpeta 469 no 358.

143 1511, marzo, 8. Sevilla. A.H.N. OO.MM. Calatrava. Códices. Sign. 813 b. Fols. 60 ro y 13 vº. 


\section{Priores de Santa María de los Mártires}

1.- Frey Clemente: Se cita como prior de los Mártires en $1409^{144}$.

2.- Frey Bibiente de Almonasar: Se documenta como prior de Santa María de los Mártires entre 1428 y $1434^{145}$.

\section{Priores de San Benito de SeVILla}

1.- Frey Gonzalo Díaz: Se documenta como prior del Maestre en $1383^{146}$. En 1407 se cita, suponiendo que sea la misma persona, a frey Gonzalo ya como prior de las Casas de Sevilla ${ }^{147}$. Es posible que también se trate del mismo frey Gonzalo Díaz Montero que aparece únicamente como "prior", sin especificar de dónde, entre los confirmantes del fuero concedido a Almadén en 1417 por el Maestre don Luís de Guzmán ${ }^{148}$.

2.- Frey Pedro: Aparece como prior de las Casas de Sevilla en $1431^{149}$.

3.- Frey Diego: Se nombra como prior de las Casas de Sevilla entre los asistentes al capítulo general celebrado en $1443^{150}$.

4.- Frey Antón de Almodóvar: Se documenta como prior de Sevilla en $1459^{151}$. Poco después sería sustituido al frente del priorato y regresó al Convento central, ya que en 1462 se documenta como freile conventual ${ }^{152}$, mientras que ese mismo año se cita un nuevo prior de las Casas de Sevilla.

5.- Frey Alfonso de Almagro: Se documenta como prior de las Casas de Sevilla entre 1462 y $1466^{153}$. En 1489 se cita como prior de Zorita ${ }^{154}$.

${ }^{144}$ 1409, marzo, 15. Almodóvar del Campo. A.H.N. OO.MM. Calatrava. Particulares. Carpeta 466 $\mathrm{n}^{\circ} 290$.

145 -1428, septiembre. Almodóvar del Campo R.A.H. Col. Salazar, sign M-5, Fol. 279 y sign. M-9, Fols. 281-292; 1434, mayo. Almagro. Sign. M-8, Fols. 274 vo-278 ro; Rodríguez-PicaVeA, ob. cit., p. 206.

146 1383, septiembre, 8. Almagro. A.H.N. OO.MM. Calatrava. Libros manuscritos. Libro Registro de Escrituras de la Orden de Calatrava. Tomo VIII. Sign. 1348-C, n $\mathrm{n}^{\mathrm{0}} 12$. Fols. $12 \mathrm{r}^{\mathrm{o}}-13 \mathrm{v}^{\mathrm{o}}$.

${ }^{147}$ 1407, octubre, 10. Jaén. A.H.N. OO.MM. Calatrava. Particulares. Carpeta 466 nº 289.

${ }^{148}$ Corchado, ob. cit., p. 101. También es posible, sin embargo, que el frey Gonzalo citado como prior de Sevilla en 1407, sea en realidad frey Gonzalo de Almagro, citado también como "prior", en el fuero de Almadén.

149 1431, abril, 30. Sevilla. R.A.H. Col. Salazar. Sign.M-130. Fols. 61 vº-63 vº.

${ }^{150}$ Rodríguez-PicaveA, ob. cit., p. 215.

${ }_{151}^{1459}$, abril, 10. Sevilla. A.H.N. OO.MM. Calatrava. Visitas. Legajo 6109 n 9. Fols, 280 r $^{\circ}-282$ r $^{\circ}$.

${ }_{152}$ 1462, julio, 12. Calatrava la Nueva. A.H.N. OO.MM. Calatrava. Particulares. Carpeta 468 n $^{\circ}$ 350.

${ }^{153}$ 1462, marzo, 22. Porcuna. A.H.N. OO.MM. Calatrava. Particulares. Carpeta 469 n $^{\circ} 352 ; 1463$, junio, 23. Sevilla. A.H.N. OO.MM. Calatrava. Visitas. Legajo $6109 \mathrm{n}^{\circ} 13$. Fols. $264 \mathrm{r}^{\mathrm{o}}-264 \mathrm{v}^{\mathrm{o}}$; 1464, marzo, 20. Porcuna. A.H.N. Osuna. Leg. $2 \mathrm{n}^{\circ}$ 1; y, 1466, mayo. Calatrava la Nueva. A.H.N. OO.MM. Calatrava. Particulares. Carpeta $469 \mathrm{n}^{\circ} 355$.

${ }^{154}$ 1489, agosto, 3. Aldea del Rey. A.H.N. OO.MM. Calatrava. Libros manuscritos. Libro Registro de Escrituras de la Orden de Calatrava. Tomo VIII. Sign. 1348-C. Fols. 125 r $^{\mathrm{o}}$ y ss. 
6.- Frey Juan de Almagro: Se nombra en 1462 y 1469 como prior o capellán del Maestre $^{155}$. En 1472 se documenta como freile conventual ${ }^{156}$. Posteriormente, en 1485 lo encontramos con el cargo de Cantor del Convento. Ejerció como secretario en el capítulo general en el que se autorizó la incorporación del maestrazgo a la Corona ${ }^{157}$. En 1488 se documenta ejerciendo el cargo de prior de San Benito de Sevilla ${ }^{158}$, aunque no estuvo mucho tiempo al frente del priorato, ya que al año siguiente ostentaba el cargo de Sacristán Mayor ${ }^{159}$.

7.- Frey Pedro de Troya: Se cita en 1492 como prior de las Casas de Sevilla ${ }^{160}$, donde continuaba en 1502, año en que fue visitador general junto al comendador de Malagón frey Pedro de Aguayo. Consta además, que ejercía el cargo de capellán de los Reyes ${ }^{161}$. En 1509 se menciona como Sacristán Mayor ${ }^{162}$.

8.- Frey Bernardino de Lucio: Aparece como prior de Sevilla en el capítulo general de 1511, donde se dice que había sido nombrado visitador de los conventos femeninos de la Orden ${ }^{163}$.

\section{Priores de San Benito de Porcuna}

1.- Frey Pedro: Se cita en 1406 como prior de Porcuna en el poder dado por el Maestre don Enrique de Villena a frey Fernando, prior de Jaén, para acensar ciertas heredades ${ }^{164}$. Es posible que se trate del mismo frey Pedro que se cita como prior del Maestre don Gonzalo Núñez en $1395^{165}$.

2.- Frey Luis: Fue prior de San Benito de Porcuna entre 1428 y $1434^{166}$.

3.- Frey Juan Galindo: Se nombra como prior de San Benito de Porcuna en 1443. Posteriormente ejerció el cargo de Pitanciero en el Convento de Calatrava. A partir de 1466 se documenta como prior de Zuqueca ${ }^{167}$.

4.- Frey Miguel del Moral: Se cita como prior de San Benito de Porcuna entre 1459 y $1469^{168}$.

${ }^{155} 1462$, marzo, 22. Porcuna. A.H.N. OO.MM. Calatrava. Particulares. Carpeta 469 nº 352; y, 1469 , abril, 3 y 4 . Almagro.

156 1472, noviembre, 28. Almagro. A.H.N. OO.MM. Calatrava. Particulares. Carpeta 469 nº 361.

157 1485, febrero, 13. Calatrava la Nueva. Bullarium..., pp. 285-290. Scriptura I.

158 1488, julio, 5. Almagro. A.H.N. OO.MM. Calatrava. Particulares. Carpeta 469 no 368.

159 1489, agosto, 3. Aldea del Rey. A.H.N. OO.MM. Calatrava. Libros manuscritos. Libro Registro de Escrituras de la Orden de Calatrava. Tomo VIII. Sign. 1348-C. Fols. 125 r $^{\circ}$ y ss.

160 1492, octubre, 4. Sevilla. A.H.N. OO.MM. Consejo. Calatrava. Visitas. Legajo 6109 nº 18. Fol. $5 \mathrm{r}^{\circ}$.

${ }^{161}$ Véase, por ejemplo, 1502, febrero, 28. La Calzada. A.H.N. OO.MM. Consejo. Calatrava. Visitas. Legajo. 6.075, $\mathrm{n}^{\circ} 28$. $\mathrm{n}^{\mathrm{o}} 39$.

162 1510, marzo. La Calzada, Iglesia. A.H.N. OO.MM. Consejo. Calatrava. Visitas. Legajo. 6.076,

163 1511, marzo, 8. Sevilla. A.H.N. OO.MM. Calatrava. Códices. Sign. 813 b. Fols, 16 ro -16 vo .

164 1407, octubre, 10. Jaén. A.H.N.O OO.MM. Calatrava. Particulares. Carpeta 466 nº 289.

165 1395, junio, 6. Almagro. A.H.N. OO.MM. Calatrava. Particulares. Carpeta 466 no 276.

${ }^{166}$ RodríGUEZ-PiCAVEA, ob. cit., p. 227.

${ }^{167}$ Id. p. 217.

${ }^{168}$ 1459, marzo, 26. Porcuna. A.H.N. OO.MM. Calatrava. Visitas. Legajo 6109 no 8. Fols. 247 ro$250 \mathrm{v}^{\mathrm{o}} ; 1462$, marzo, 22. Porcuna. Particulares. Carpeta $469 \mathrm{n}^{\circ} 352 ; 1464$, marzo, 20. Porcuna. Osuna. 
5.- Frey Juan de Cuenca: Se menciona como freile conventual en 1462 y $1466^{169}$. Se nombra como prior de San Benito de Porcuna en $1488^{170}$, y como prior de San Benito y administrador del priorato de Santa María de La Coronada entre 1493 y $1508^{171}$. En 1501 pudo haber tenido también a su cargo el priorato de Santa Fe de Granada $^{172}$.

6.- Frey Martín de Corpa: En 1492 se cita como capellán de una de las capellanías que fundó en el priorato de San Benito de Sevilla frey Juan de las Roelas ${ }^{173}$. Sustituyó al frente del priorato de San Benito de Porcuna a frey Juan de Cuenca. Frey Martín, además de prior de Porcuna, era en 1511 capellán de los Reyes ${ }^{174}$.

\section{Priores de Santa María de La Coronada de Porcuna}

1.- Frey Fernando de Montoro: Se cita como prior de La Coronada entre 1459 y $1466^{175}$. Con anterioridad ejerció el cargo de prior de Santa María de Fuencaliente, título con el que se nombra en $1443^{176}$.

2.- Frey Juan de Cuenca: Se nombra como administrador del priorato a partir de 1492, aunque la comisión para el cargo se la dio el Maestre don García López de Padilla, con lo que se puede retraer la fecha al menos hasta 1488 en que se cita por primera vez a frey Juan de Cuenca como prior de San Benito de Porcuna ${ }^{177}$. Sería entonces, o poco después, cuando recibió La Coronada en administración. Frey Juan de Cuenca estuvo al frente del priorato al menos hasta $1508^{178}$. En 1511 ya existía otro prior distinto del de San Benito de Porcuna, aunque no hemos podido localizar su nombre ${ }^{179}$.

\section{Priores de SAN Benito de JAÉN}

1- Frey Fernando: Se menciona como prior de San Benito de Jaén en el documento de 1407 anteriormente citado.

Leg. 2 , nº 1 ; y 1469, abril, 3 y 4. Almagro. Calatrava. Particulares. Carpeta 469 n 358.

169 1462, julio, 12. Calatrava la Nueva. A.H.N. OO.MM. Calatrava. Particulares. Carpeta $468 \mathrm{n}^{\circ}$ 350; y, 1466, mayo. Calatrava la Nueva. Carpeta 469 n 355.

170 1488, julio, 5. Almagro. A.H.N. OO.MM. Calatrava. Particulares. Carpeta 469 no 368.

171 1492, octubre, 27. Porcuna. A.H.N. OO.MM. Consejo. Calatrava. Visitas. Legajo 6109 n $^{\circ} 19$. Fols, $21 r^{\circ}-35 r^{\circ} ; 1495$, Porcuna. $n^{\circ} 30$. Fols. $142 r^{\circ}-146 v^{o}$; 1499, abril, 4. Porcuna. ${ }^{\circ} 55$. Fols. $77 r^{\circ}-84$ $\mathrm{v}^{\mathrm{o}}$; y, 1511, marzo, 8. Sevilla. Códices. Sign. 813 b. Fol. 40 vo .

172 1501, Julio, 15. Granada. A.G.S. CCA, CED, 5, 188, 5.

173 1492, octubre, 4. Sevilla. A.H.N. OO.MM. Consejo. Calatrava. Visitas. Legajo 6109 nº 18. Fols. $1 \mathrm{r}^{\mathrm{o}}-9 \mathrm{v}^{\mathrm{o}}$.

${ }^{174}$ Id. Fols. $40 \mathrm{r}^{\mathrm{o}}, 76 \mathrm{v}^{\mathrm{o}}-78 \mathrm{r}^{\mathrm{o}}$, y $19 \mathrm{r}^{\mathrm{o}}$.

175 1459, marzo, 26. Porcuna. A.H.N. OO.MM. Calatrava. Visitas. Legajo 6109 no 8. Fols, 251 r $^{\circ}-253$

ro; y, 1466, mayo. Calatrava la Nueva. A.H.N. OO.MM. Calatrava. Particulares. Carpeta 469 no 355.

${ }^{176}$ RodríGuez-PicaveA, ob. cit., p. 229.

177 1488, julio, 5. Almagro. A.H.N. OO.MM. Calatrava. Particulares. Carpeta 469 nº 368.

178 1492, octubre, 27. Porcuna. A.H.N. OO.MM. Consejo. Calatrava. Visitas. Legajo 6109 n $^{\circ} 19$. Fols, 21 r $^{\mathrm{o}}-35$ ro $;$ y, 1511, marzo, 8. Sevilla. A.H.N. OO.MM. Calatrava. Códices. Sign. 813 b. Fol, 40 v $^{\circ}$.

${ }^{179}$ Id. Fol. $19 \mathrm{r}^{\mathrm{o}}$. 
2.- Frey Miguel del Moral: Se nombra como prior de Jaén en 1433, en el capítulo que pidió al abad de Morimundo que confirmara a don Alonso de Aragón como Maestre de la Orden ${ }^{180}$. En 1459 se cita como prior de San Benito de Porcuna, aunque había dejado el priorato de Jaén con anterioridad, pues se documenta otro prior al frente del priorato en $1451^{181}$.

3.- Frey Bartolomé de Almodóvar: Era freile conventual en $1443^{182}$. Como prior de San Benito de Jaén se documenta en 1451, año en que fue promovido a la Sacristanía Mayor ${ }^{183}$.

4.- Frey Aparicio de Almodóvar: Se cita como freile clérigo en $1443^{184}$. Entre 1445 y 1448 fue pitanciero del Convento de Calatrava ${ }^{185}$. Aparece como prior de Jaén entre 1462 y $1475^{186}$.

5.- Frey Rodrigo del Moral: Se documenta como freile clérigo en 1462 y $1466^{187}$. Se cita al frente del priorato de San Benito de Jaén entre 1488 y $1510^{188}$. En 1495 fue comisionado para visitar las iglesias y villas calatravas del obispado de Jaén junto con el obispo, siguiendo las disposiciones del Capítulo celebrado en 1492 en San $\mathrm{Fe}^{189}$. En 1507 ejercía el cargo de administrador del Priorato del Convento que estaba vacante por nombramiento del Comendador Mayor don Gutierre de Padilla, hasta que el abad de Morimundo proveyese un nuevo Prior ${ }^{190}$.

\section{Priores de Santa fe de Granada}

1.- Frey Juan de Cuenca, Se cita como prior de Santa fe de Granada en 1501. Era, también, prior de San Benito de Porcuna y administrador del de Santa María de La

${ }^{180}$ 1443. Calatrava la Nueva. A.H.N. OO.MM. Calatrava. Particulares. Carpeta 467 n 321 bis; y, Rodríguez-PicAVEA, ob. cit., p. 229.

181 1459, marzo, 26. Porcuna. A.H.N. OO.MM. Calatrava. Visitas. Legajo 6109 nº 8. Fols. 247 ro$250 \mathrm{v}^{\mathrm{o}}$.

182 1443. Calatrava la Nueva. A.H.N. OO.MM. Calatrava. Particulares. Carpeta 467 n 321 bis; RodrígUEZ-PiCAVEA, ob. cit., pp. 205.

183 1451, abril, 2. Magán. A.H.N. OO.MM. Calatrava. Particulares. Carpeta 468 nº 338.

184 1443. Calatrava la Nueva. A.H.N. OO.MM. Calatrava. Particulares. Carpeta 467 n 321 bis; RODRÍGUEZ-PICAVEA, ob.cit.

185 1445, octubre, 21. La Calzada. A.H.N. OO.MM. Calatrava. Particulares. Carpeta 468 nº 328; y, 1448, septiembre, 11. Argamasilla de Calatrava. n 333.

186 1462, marzo, 22. Porcuna. A.H.N. OO.MM. Calatrava. Particulares. Carpeta 469 n 352; 1463 , junio, 14. Jaén. A.H.N. OO.MM. Calatrava. Visitas. Legajo 6109 n ${ }^{\circ} 12$. Fols. 175 ro -178 vo; 1464, marzo, 20. Porcuna. A.H.N. Osuna. Leg. $2 \mathrm{n}^{\circ}$ 1; y, 1469, abril, 3 y 4. Almagro A.H.N. OO.MM. Calatrava. Particulares. Carpeta 469 n ${ }^{\circ}$ 358; JAVIERre Mur, A. "El Priorato de San Benito de Jaén de la Orden de Calatrava" en, Boletín del Instituto de Estudios Jiennenses. Año III, no 8 (1956), pp. 9-10.

187 1462, marzo, 22. Porcuna. A.H.N. OO.MM. Calatrava. Particulares. Carpeta 469 nº 352; y, 1466, mayo. Calatrava la Nueva. no 355 .

188 1488, julio 5. Almagro. A.H.N. OO.MM. Calatrava. Particulares. Carpeta 469 nº 368; 1492 , diciembre, 8. Jaen. A.H.N. OO.MM. Consejo. Calatrava. Visitas. Legajo 6109 n $^{\circ} 21$. Fols, 57 ro -60 ro; y, 1510, marzo, 21. La Calzada. Cofradías, A.H.N. OO.MM. Consejo. Calatrava. Visitas. Legajo. 6.076 $\mathrm{n}^{\mathrm{o}} 40$. Fols. $216 \mathrm{r}^{\mathrm{o}}-228 \mathrm{v}^{\mathrm{o}}$.

189 1495, agosto, 8. Burgos. A.G.S. CCA, CED 3-2, 69, 2. 1495, agosto, 8. Burgos. p. 269.

${ }^{190}$ Diffiniciones de la Orden y Cavalleria de Calatrava conforme al Capitulo General..., ob. cit., 
Coronada, y en la fecha señalada fue encargado de hacer cierta información sobre la cátedra de Teología que existía en el Convento de Calatrava la Nueva ${ }^{191}$.

\section{Priores DE AlCAÑIZ}

1.- Frey Domingo: Se cita como prior de Alcañiz en 1267, en la concordia entre la Orden y el obispo de Zaragoza ${ }^{192}$.

2.- Frey Alonso de Arroyo: En 1493 se encontraba al frente del priorato de Santa Fe de Toledo ${ }^{193}$. Dos años después se nombra como prior de Alcañiz, ostentando el cargo por lo menos hasta $1501^{194}$.

3.- Frey Diego Bermúdez: Aparece como prior de Alcañiz en 1511, cuando fue nombrado visitador del reino de Aragón junto con el comendador de Burriana frey Martín de Vizana ${ }^{195}$.

\section{Priores de las Casas de Valencia}

1.- Frey Pedro de Alcañiz: Se documenta como prior de las Casas de Valencia en $1291^{196}$.

2.- Frey Gil de Molina: Se cita como prior de Toledo en $1489^{197}$. Entre 1493 y 1501 se documenta al frente del priorato de las Casas de Valencia. En 1500 ó 1501 ejerció el oficio de visitador de los reinos de Aragón y Valencia junto con el comendador frey Gutierre de Encinas. ${ }^{198}$.

3.- Frey Pedro de Neira: Aparece como prior de las Casas de Valencia en 1501, en que ejerció como visitador de los bienes y rentas de la Mesa maestral junto con el comendador de Malagón frey Pedro de Aguayo ${ }^{199}$.

\subsection{CAPELLANES DE LOS REYES}

1.- Frey Francisco: Se cita como Capellán de los Reyes en $1462^{200}$.

${ }^{191}$ 1501, Julio, 15. Granada.A.G.S. CCA, CED, 5, 188, 5.

192 1276, enero, 21. Alcañiz. Bullarium... pp. 138-142. Scriptura VII. Después del prior, se relaciona una serie de freiles que pudieran ser clérigos del convento aragonés:... Et Nos Fratres Rodericus Petri Pontii Commendator praedictus, et Fratrer Eximinus Pardi Commendator de... Fratrer Dominicus Prior de Alcannicio, Fratrer Lupus Arcer, Fratrer Gundisalvus, Fratrer Petrus Joannis, et Fratrer Bernardus Ordinis Calatravae, omnia praedicta, et singula laudamus...

${ }^{193}$ 1493, mayo, 19. Toledo. A.H.N. OO.MM. Consejo. Calatrava. Visitas. Legajo 6109 no 24. Fols. $251 \mathrm{r}^{\circ}-252 \mathrm{v}^{\mathrm{o}}$.

194 1495, marzo, 33. Madrid. A.G.S. CCA, CED, 3-2, 66, 2; y, 1501, marzo, 20. Granada. CCA, CED, $5,72,6$.

195 1511, marzo, 8. Sevilla. A.H.N. OO.MM. Calatrava. Códices. Sign. 813 b. Fol, 16 ro

196 1291, julio, 23. R.A.H. Col. Salazar. Sign I-40. Fols. 306-307. Copia en valenciano.

197 1489, enero, 1. Almagro. A.H.N. OO.MM. Calatrava. Particulares. Carpeta 469 nº 370.

198 1493, febrero, 22. Barcelona. A.G.S. CCA, CED, 3-2,1, 4; y, 1501, febrero, 2. Granada.

CCA, CED, 5, 25, 2.

199 1501, febrero, 2. Granada. A.G.S. CCA, CED, 3-2, 40, 2.

${ }^{200}$ 1462, julio, 12. Calatrava la Nueva. A.H.N. OO.MM. Calatrava. Particulares. Carpeta 468 n $^{\circ}$ 350 . 
2.- Frey Pedro de Troya: Entre 1492 y 1502 fue prior de las Casas de Sevilla ${ }^{201}$, constando, además, que ejercía el cargo de Capellán de los Reyes ${ }^{202}$.

3.- Frey Martín de Corpa: En 1492 se documenta como capellán de una de las capellanías que fundó frey Juan de las Roelas, comendador de las Casas de Sevilla ${ }^{203}$. Posteriormente sustituyó al frente del priorato de San Benito de Porcuna a frey Juan de Cuenca. Además de prior de Porcuna frey Martín era Capellán de los Reyes en $1511^{204}$.

\subsection{PRIORATOS PERSONALES}

\section{Priores del Maestre}

1.- Frey Pedro: Se documenta en 1395 como prior del Maestre don Gonzalo Núñez de Guzmán ${ }^{205}$. Es posible que fuera el mismo frey Pedro que asistió al capítulo celebrado en Porcuna en $1406^{206}$.

2.- Frey Gonzalo: Se nombra como prior del Maestre don Luis González de Guzmán entre los asistentes al capítulo celebrado en 1417 en la iglesia de Santa María de los Llanos de Almagro ${ }^{207}$.

3.- Frey Bartolomé de Almagro: Se cita como freile clérigo en $1443^{208}$, y como prior del Maestre entre 1460 y $1464^{209}$.

4.- Frey Alonso: se cita como prior del Maestre en 1466 en el testamento de Don Pedro Girón ${ }^{210}$.

5.- Frey Juan de Almagro: Fue prior del Maestre entre 1462 y $1469^{211}$. Posteriormente se cita en 1472 como freile conventual ${ }^{212}$, y en 1485 como Cantor del Convento de Calatrava ${ }^{213}$. En 1488 ostentaba el cargo de Prior de San Benito de Sevilla ${ }^{214}$, aunque no estuvo mucho tiempo al frente del priorato, ya que se cita al año siguiente como Sacristán Mayor ${ }^{215}$.

${ }^{201}$ 1492, octubre, 4. Sevilla. A.H.N. OO.MM. Consejo. Calatrava. Visitas. Legajo 6109 nº 18. Fol. 5 ro.

${ }^{202}$ Véase, por ejemplo, 1502, febrero, 28. La Calzada. A.H.N. OO.MM. Consejo. Calatrava. Visitas. Legajo. 6.075, $\mathrm{n}^{\circ} 28$.

${ }^{203}$ 1492, octubre, 4. Sevilla. A.H.N. OO.MM. Consejo. Calatrava. Visitas. Legajo 6109 no 18. Fols, $1 \mathrm{r}^{\mathrm{o}}-9 \mathrm{v}^{\mathrm{o}}$.

${ }^{204}$ 1511, marzo, 8. Sevilla. A.H.N. OO.MM. Calatrava. Códices. Sign. 813 b. Fol. 19 ro

${ }^{205}$ 1395, junio, 6. Almagro. A.H.N. OO.MM. Calatrava. Particulares. Carpeta 466 no 275.

206 1406, julio, 1. Porcuna. A.H.N. OO.MM. Calatrava. Particulares. Carpeta 466 nº 284.

${ }^{207}$ 1417, diciembre. Almagro. A.H.N. OO.MM. Calatrava. Particulares. Carpeta 467 nº 297.

208 1443. Calatrava la Nueva. A.H.N. OO.MM. Calatrava. Particulares. Carpeta 467 no 321 bis.

209 1460, enero 11. Valdepeñas. A.H.N. Osuna. Leg. 41 n 11 ; y, 1464, marzo, 20. Porcuna. Leg. 2 $\mathrm{n}^{\mathrm{o}} 1$.

${ }^{210}$ ViÑA, ob. cit.,

211 1462, marzo, 22. Porcuna. A.H.N. OO.MM. Calatrava. Particulares. Carpeta 469 no 352; y, 1469 , abril, 3 y 4 . Almagro. $n^{\circ} 358$.

212 1472, noviembre, 28. Almagro. A.H.N. OO.MM. Calatrava. Particulares. Carpeta 469 no 361.

${ }^{213}$ 1485, febrero, 13. Calatrava la Nueva. Bullarium..., pp. 285-290. Scriptura I.

${ }^{214}$ 1488, julio, 5. Almagro. A.H.N. OO.MM. Calatrava. Particulares. Carpeta 469 no 368.

${ }^{215}$ 1489, agosto, 3. Aldea del Rey. A.H.N. OO.MM. Calatrava. Libros manuscritos. Libro Registro de Escrituras de la Orden de Calatrava. Tomo VIII. Sign. 1348-C. Fols. 125 r $^{\circ}$ y ss. 


\section{Priores del Comendador Mayor}

1.- Frey Juan de Bolaños. Éste freile clérigo se documenta como freile clérigo en $1443^{216}$. Se cita como prior de El Collado en $1466^{217}$. Como prior del Comendador Mayor se nombra en $1469^{218}$.

PRIORES DEL ClAVERO

1.- Frey Pedro: Se cita como prior del Clavero frey Ramiro Núñez de Guzmán en $1417^{219}$.

\subsection{CAPELLANES DE SEVILLA}

1.- Frey Miguel de Almodóvar: Se cita como capellán en $1492^{220}$. Debió fallecer ese mismo año o a comienzos del siguiente, ya que en marzo de 1493 se solicitaba al Prior del Convento, información sobre un freile conventual, que fuese hábil y suficiente, para proveer la capellanía que había dejado vacante por fallecimiento frey Miguel de Almodóvar ${ }^{221}$.

2.- Frey Martín de Corpa: Se nombra igualmente en 1492 como capellán ${ }^{222}$. Después sería nombrado prior de San Benito de Porcuna y capellán de los Reyes.

3.- Frey Pedro Chacón: Aparece como capellán de Sevilla en las actas del capítulo general de Sevilla de 1511.

4.- Frey Alfonso de Jaén: Se nombra como capellán en el capítulo general de 1511, aunque ya había fallecido.

5.- Frey Hernán García: Se cita como capellán en el capítulo general de Sevilla de 1511 , aunque también consta que había fallecido ${ }^{223}$.

216 1443. Calatrava la Nueva. A.H.N. OO.MM. Calatrava. Particulares. Carpeta 467 no 321 bis.

217 1466. mayo. Calatrava la Nueva. A.H.N. OO.MM. Calatrava. Particulares. Carpeta 469 no 355.

${ }^{218}$ 1469, abril, 3 y 4. Almagro. A.H.N. OO.MM. Calatrava. Particulares. Carpeta 469 nº 358. 1469.

${ }^{219}$ RodríGUEZ-PicAVEA, ob. cit., p. 234.

${ }^{220}$ Id. Fol. 3 ro.

${ }^{221}$ 1493, marzo, 18. Medina del Campo. A.G.S. CCA, CED, 3-2, 40, 2.

222 1492, octubre, 4. Sevilla. A.H.N. OO.MM. Consejo. Calatrava. Visitas. Legajo 6109 n ${ }^{\circ} 18$. Fol. 3 ro.

${ }^{223}$ 1511, marzo, 8. Sevilla. A.H.N. OO.MM. Calatrava. Códices. Sign. 813 b. Fol. 19 ro, 45 ró y 75 $\mathrm{r}^{\mathrm{o}}-75 \mathrm{v}^{\mathrm{o}}$. 